\title{
Isolation, Characterization and Evaluation of Ocimum Basilicum Seed Mucilage for Tableting Performance
}

\author{
F. J. SAYYAD AND SFURTI S. SAKHARE* \\ Department of Pharmaceutics, Government College of Pharmacy, Karad-415 124, India
}

\author{
Sayyad and Sakhare: Ocimum Basilicum Mucilage as a Tablet Excipient
}

\begin{abstract}
Owing to multifarious potentialities and fine aroma chemicals, Ocimum basilicum possessed medicinal properties like antibiotic, antistress, diaphoretic, diuretic, antipyretic, stomachic, antimicrobial and insecticidal. The main aim of this study was to isolate and characterize mucilage obtained from Ocimum basilicum seeds as a pharmaceutical excipient. Phytochemical characterization of the isolated mucilage was performed and presence of carbohydrates, fats and oils was detected using identification tests. Compressibility performance of the isolated mucilage was evaluated using the Heckel plot study, which showed that the isolated mucilage has poor compressibility properties. Results indicated that the mucilage could be a potential superdisintegrant for formulating fast disintegrating tablets of metoprolol tartarate. The way of addition of mucilage, concentration and the method of preparation all were found to influence fast disintegrating tablet performance. From these results it is possible to conclude that Ocimum basilicum seed mucilage could be used in direct compression with other excipients and in wet granulation technology as a superdisintegrant.
\end{abstract}

Key words: Ocimum basilicum, extraction, mucilage, disintegrant

Herbal products appear to be more preferred over synthetic ones due to their accessibility, biocompatibility, low cost and low toxicity potential. Mucilage's and gums obtained from natural sources are most widely used as pharmaceutical excipients due to their binding, diluent and disintegrant properties in tablets, due to suspending and gelling properties in gels and due to thickening properties in oral liquids ${ }^{[1-3]}$. Mucilage's are used for their binding, thickening, stabilizing, humidifying, disintegrating and releasecontrolling properties in medicines ${ }^{[3,4]}$.

Ocimum basilicum is highly valued for its medicinal and aromatic properties in the traditional as well as modern medicinal system. Ocimum includes aromatic herbs, under shrubs and shrubs yielding essential oils of various aroma chemicals, which are of tremendous value in pharmaceutical, modern perfumery and food processing industry. The plant of $O$. basilicum is stomachic, stimulant, carminative, antipyretic, diaphoretic, expectorant, diuretic and also useful in heart, brain and blood diseases, asthma, inflammations and enlarged spleen ${ }^{[5]}$.

Essential oil of $O$. basilicum is of economic significance due to its widespread utilization in food, cosmetics and pharmaceutical industries. It is used as a folklore medicine to promote digestion, to stimulate respiratory circulation, and to alleviate mental fatigue and cold symptoms. It is also applied externally on the skin to treat acne. Many studies investigated the potential of basil essential oil as an antimicrobial agent ${ }^{[6]}$. Basil seed gum mainly consisted of some high molecular weight polysaccharides $(2320 \mathrm{kDa})$, which was composed of glucose, galactose, mannose, arabinose, xylose and rhamnose ${ }^{[7]}$. Basil seed gum appears to be a very interesting raw material for the preparation of edible films and coatings. These films could serve as a potential alternative for synthetic packaging, mainly for the purpose of storing foods with low or intermediate moisture such as nuts ${ }^{[8]}$. O. basilicum has been found to be a highly effective coagulating agent for the treatment of textile waste water ${ }^{[9]}$. The present investigation involved isolation of mucilage from $O$.

This is an open access article distributed under the terms of the Creative Commons Attribution-NonCommercial-ShareAlike 3.0 License, which allows others to remix, tweak, and build upon the work non-commercially, as long as the author is credited and the new creations are licensed under the identical terms

Accepted 29 January 2018

Revised 02 June 2017

Received 22 December 2016

Indian J Pharm Sci 2018;80(2):282-290 
basilicum seeds followed by phytochemical screening and physicochemical analysis. Further the mucilage was evaluated for tableting performance using the Heckel plot study. Since this mucilage was reported as a superdisintegrant ${ }^{[10]}$ in formulation of tablets, the present investigation also explored optimization of concentration of mucilage in formulation of metoprolol tartarate tablets in comparison with synthetic superdisintegrants and to study the effect of method of manufacturing.

\section{MATERIALS AND METHODS}

The $O$. basilicum seeds were procured from Green Pharmacy, Pune. Metoprolal tartarate was obtained as a gift sample from Lupin Laboratories Ltd., Pune. All other reagents were of analytical grade and purchased from Loba Chemie Pvt. Ltd., Mumbai.

\section{Isolation and purification of $\boldsymbol{O}$. basilicum mucilage:}

$O$. basilicum seeds were cleaned by washing with distilled water followed by soaking in $500 \mathrm{ml}$ of distilled water with intermittent stirring for 12-14 h until they became soft. The soft seed material was subjected to slow stirring using an overhead stirrer (Remi, India) and seedless white-colored mucilaginous material was collected by filtering through muslin cloth. The so collected mucilage was purified by precipitation with $250 \mathrm{ml}$ of $95 \%$ ethanol. The mucilage precipitate was dried in the oven at $50-55^{\circ}$ for $4-5 \mathrm{~h}$. Dried mucilage was scraped with a spatula, powdered in a mortar and pestle, sieved through a mesh no. 60 and stored in a desiccator for further studies.

\section{Characterization of isolated $\boldsymbol{O}$. basilicum mucilage:}

To check the efficiency of the method of isolation, the product yield was determined. The yield of the extracted soluble part of mucilage was determined by weighing the dried extracted mucilage. Yield = $100 \times$ mass of extracted gum $(\mathrm{g}) /$ mass of seed $(\mathrm{g})$.

The following properties of the mucilage were studied to confirm its nature. The solubility of the separated mucilage was studied in various solvents. One part of dry mucilage was shaken with different solvents and the solubility was determined. Loss on drying is the loss of mass expressed as percent $\mathrm{w} / \mathrm{w}$. The test for loss on drying determines both water and volatile matter in the crude material. An accurately weighed quantity $(5 \mathrm{~g})$ of mucilage was taken in a tarred porcelain and was kept in an oven to dry the sample at $110^{\circ}$ for
$2 \mathrm{~h}$ until a constant weight was obtained. Then it was cooled in a desiccator to room temperature, weighed and recorded. Percent loss on drying was calculated using the following Eqn., loss on drying $(\%)=$ loss in weight of the sample/weight of sample $\times 100$.

Ash values are indicative of the quality and purity of a crude drug, especially in the powdered form. The objective of ashing vegetable drugs is to remove all traces of organic matter, which may otherwise interfere in analytical determination. On incineration, crude drugs normally leave an ash usually consisting of carbonates, phosphates and silicates of sodium, potassium, calcium and magnesium. A higher limit of acid-insoluble ash is imposed, especially in cases where silica may be present or when the calcium oxalate content of the drug is very high. Specified quantity of mucilage was taken in a tarred silica crucible. It was then incinerated at a temperature not exceeding $450^{\circ}$ for $4 \mathrm{~h}$, until free from carbon, cooled and weighed. The percent ash was calculated with reference to air-dried drug using the following Eqn., total ash value (\%) = weight of total ash/weight of crude drug taken $\times 100$.

\section{Water-soluble ash value:}

The specified quantity of ash was boiled with $25 \mathrm{ml}$ of water. The insoluble matter was filtered and collected on an ash less filter paper, washed with hot water and ignited in a tarred crucible at a temperature not exceeding $450^{\circ}$ for $4 \mathrm{~h}$. The insoluble matter was cooled in a desiccator, weighed and subtracted from the total weight of ash. The difference in weight represented weight of water-soluble ash. The percent water-soluble ash was calculated with reference to the air-dried drug using the following Eqn., water-soluble ash value (\%) = weight of total ash-weight of water-insoluble ash/ weight of crude drug taken $\times 100$.

\section{Acid-insoluble ash value:}

Acid-insoluble ash value was determined by boiling the specified quantity of ash for 5 min with $25 \mathrm{ml}$ of $2 \mathrm{M} \mathrm{HCl}$. The insoluble matter was filtered and collected on an ash less filter paper, washed with hot water and ignited in a tarred crucible at a temperature not exceeding $450^{\circ}$ for $4 \mathrm{~h}$. The insoluble matter was cooled in desiccators and weighed. The percent acidinsoluble ash was calculated with reference to the airdried drug using the following Eqn., acid-insoluble ash value $(\%)=$ weight of acid-insoluble ash/weight of crude drug taken $\times 100$. 


\section{Fourier-transform infrared spectroscopy (FTIR) spectroscopy:}

The FTIR spectrum of the $O$. basilicum mucilage was recorded on an FTIR (Alpha-E, and Bruker) spectrometer. The base line correction was done by blank background measurement, and then the spectrum of dried mucilage was run. By running the IR spectra of drug and polymer it will help in identifying the groups and also help in detecting if any interaction occurs between the reagents.

\section{Powder X-ray diffractometer (PXRD) analysis of mucilage:}

PXRD study was performed to confirm the nature of sample. The XRD used for the present study was from Seifert \& Co. D 2070, Ahrensburg. The target material of the instrument was copper $(\mathrm{Cu})$ and nickel was used as the filter and a voltage of $35 \mathrm{kV}$ and a current of $30 \mathrm{~mA}$ was used. PXRD patterns were traced for $O$. basilicum mucilage, which will help in identifying the nature of mucilage.

\section{Differential scanning calorimetry (DSC) analysis of mucilage:}

The DSC scan of $O$. basilicum mucilage of about $5 \mathrm{mg}$ was performed in dry $\mathrm{N}_{2}$ atmosphere by using Shimadzu (Tokyo, Japan) at scanning range of $10^{\circ} / \mathrm{min}$ from $50-300^{\circ}$. It will help in understanding if any polymorphic transition occurs.

\section{Determination of swelling index of $\boldsymbol{O}$. basilicum mucilage:}

Swelling index gives an idea about the mucilage content of the seed; hence it is useful in the evaluation of crude drugs containing mucilage. The swelling index is the volume in milliliter occupied by $1 \mathrm{~g}$ of drug; including any adhering mucilage after it has been swollen in an aqueous liquid for $4 \mathrm{~h}$. One gram of mucilage was taken in a $25 \mathrm{ml}$ ground glass stoppered cylinder graduated over a height of 120 to $130 \mathrm{~mm}$ in 0.5 divisions. To this $25 \mathrm{ml}$ of distilled water was added and this was shaken vigorously every $10 \mathrm{~min}$ for $1 \mathrm{~h}$ and then allowed to stand for $24 \mathrm{~h}$. The volume occupied by the disintegrating agent including adhering mucilage was measured. The swelling index was calculated from the mean of three determinations.

The particle size and size distribution of $O$. basilicum mucilage was carried out by optical microscopy method $^{[8]}$. The physics of compression is of primary importance in the formulation development. These are extremely useful derived parameters to assess the impact of change in drug powder properties as new batches become available ${ }^{[9]}$.

The $O$. basilicum mucilage was evaluated for the precompression parameters such as measurement of angle of repose, bulk density, tapped density, compressibility index, flow rate and Hausner ratio. The angle of repose of the powder was determined by fixed funnel method to assess the flow property of the powder. Bulk and tapped density were determined using digital bulk density apparatus. The compressibility index and the Hausner ratio are determined by measuring both the bulk volume and tapped volume of a powder ${ }^{[1]}$.

\section{Heckel plot study of $\boldsymbol{O}$. basilicum mucilage:}

In both engineering and pharmaceutical sciences, the relationship between volume and applied pressure during compression is the main approach to deriving a mathematical representation of the compression pressure. The most recognized expression in both engineering and pharmaceutical science is the tablet porosity-applied pressure function according to Heckel ${ }^{[12]}$. Compaction behaviour of raw materials, crystals, and spherical agglomerates were analysed by Heckel Eqn. ${ }^{[13,14]}$. Tablet porosity can be measured either on an ejected tablet or on a powder column under load, i.e. in die. The compression of a powder can be described in terms of a first-order reaction where the pores are the reactant and the densification the product. Based on this assumption, the following expression was derived: In $(1 / \mathrm{E})=\mathrm{KP}+\mathrm{A}$, where, $\mathrm{E}=$ tablet porosity, $\mathrm{P}=$ applied pressure, $\mathrm{A}=$ constant suggested to reflect particle rearrangement $=$ slope of the linear part of the relationship, which is suggested to reflect the deformation of particles during compression.

The reciprocal of the slope value is often calculated and considered to represent the yield stress or yield pressure (Py) for the particles, i.e.: In $(1 / \mathrm{E})=$ $(\mathrm{P} / \mathrm{Py})+\mathrm{A}$. The yield pressure is defined as the stress at which particle plastic deformation is initiated ${ }^{[12]}$. The Heckel plot Eqn. is widely used to calculate the volume reduction of material when pressure is applied during compression ${ }^{[13,14]}$. The Heckel plot study of $O$. basilicum mucilage was carried out as follows: the dried isolated mucilage powder was taken. Accurately weighed $500 \mathrm{mg}$ of dry powder was compressed on hydraulic pressure using $13 \mathrm{~mm}$ flat faced punches and die. Pressure was set at the 25, 34.28, 51.42, 68.57, 
$85.71,102.85$ and $120 \mathrm{~kg} / \mathrm{cm}^{2}$. Thickness and diameter of compressed powder was measured. After releasing the tablet elastic recovery (ER) was calculated. Immediately after compression, crushing strength was measured by using tablet strength tester to determine the tablet strength $(\varphi)^{[13,14]}$.

Preparation of metoprolol tartarate fast disintegrating tablets (FDT) by direct compression technique:

Pure drug metoprolol tartarate, O. basilicum seed mucilage, Avicel pH 102, talc, magnesium stearate and sodium saccharin were passed through sieve no. 60 separately. Accurately weighed quantity of drug, mucilage and Avicel pH 102 were mixed together. After proper mixing talc (glidant), magnesium stearate (lubricant) and sodium saccharin (sweetener) were added. Powder blends of different concentrations of mucilage were prepared as shown in Table 1. The prepared powder blends were then evaluated for pre-compression parameters. After pre-compression analysis tablets were prepared on KBR press using $8 \mathrm{~mm}$ die at 1 ton of compression forces. Similar procedure was followed for the tablets prepared using synthetic superdisintegrants i.e. croscarmellose sodium (CCS) and sodium starch glycolate (SSG). The formulation batches are shown in Table 1 .

\section{Preparation of tablets by wet granulation technique:}

Accurately weighed quantity of drug, Avicel pH 102 and mucilage as shown in Table 2, was taken and dry mixed together to achieve homogenized mixing (intragranular disintegrant addition). Then water was added to form wet mass of the powder mixture. This wetted mass was passed through a sieve no. 22 and then dried in an oven. Thus granules of uniform size range were obtained. The prepared granules are then dry-mixed with disintegrant, mucilage (extragranular disintegrant addition). Then common excipients like lubricant, glidant and sweeteners were added in this final mixing operation. Then prepared granules were taken for tablet production by pre-compression evaluation. Two batches were prepared by changing mucilage concentration on KBR press using flat punches and $8 \mathrm{~mm}$ die.

\section{Pre-compression and post-compression evaluation:}

The powder blends and granules were evaluated for the measurement of angle of repose, bulk density, tapped density, compressibility index, flow rate and Hausner ratio. As these are extremely useful derived parameters for the study of pharmaceutical powders. The tablets prepared by direct compression and wet granulation technique were evaluated for various quality control parameters like thickness, hardness, weight uniformity, friability, disintegration time, wetting time, water absorption ratio, content uniformity and in vitro dissolution studies ${ }^{[11,15-17]}$

Wetting time and water absorption ratio was determined by folding a piece of tissue paper twice was placed in a small Petri dish containing $6 \mathrm{ml}$ of water. A tablet was placed on the paper and the time taken for complete wetting of tablet was noted. Three tablets from each formulation were randomly selected and the average wetting time was noted. The wetted tablets were taken and water absorption ratio was calculated by using following Eqn., $\mathrm{R}=100$ (wa-wa)/wb, where, wb=

TABLE 1: BATCHES OF FDTS OF METOPROLOL TARTARATE USING O. BASILICUM MUCILAGE AND SYNTHETIC SUPERDISINTEGRANTS (TOTAL WEIGHT= $250 \mathrm{mg}$ )

\begin{tabular}{lcccccccc}
\hline $\begin{array}{l}\text { Formulation } \\
\text { code }\end{array}$ & $\begin{array}{c}\text { Drug } \\
(\mathbf{m g})\end{array}$ & $\begin{array}{c}\text { Avicel } \\
\mathrm{pH} 102(\mathbf{m g})\end{array}$ & $\begin{array}{c}\text { Mucilage } \\
(\mathbf{m g})\end{array}$ & $\begin{array}{c}\text { CCS } \\
(\mathbf{m g})\end{array}$ & $\begin{array}{c}\text { SSG } \\
(\mathbf{m g})\end{array}$ & $\begin{array}{c}\text { Talc } \\
(\mathbf{m g})\end{array}$ & $\begin{array}{c}\text { Magnesium } \\
\text { stearate }(\mathbf{m g})\end{array}$ & $\begin{array}{c}\text { Sodium } \\
\text { saccharin }(\mathbf{m g})\end{array}$ \\
\hline F1 & 100 & 87 & 45 & - & - & 8 & 5 & 5 \\
F2 & 100 & 82 & 50 & - & - & 8 & 5 & 5 \\
F3 & 100 & 77 & 55 & - & - & 8 & 5 & 5 \\
F4 & 100 & 72 & 60 & - & - & 8 & 5 & 5 \\
F5 & 100 & 122 & - & 10 & - & 8 & 5 & 5 \\
F6 & 100 & 122 & - & - & 10 & 8 & 5 & 5 \\
\hline
\end{tabular}

CCS: Croscarmellose sodium SSG: sodium starch glycolate

TABLE 2: TABLET BATCHES BY WET GRANULATION TECHNIQUE

\begin{tabular}{lcccccc}
\hline Formulation code & $\begin{array}{c}\text { Drug } \\
(\mathbf{m g})\end{array}$ & $\begin{array}{c}\text { Avicel } \\
\mathrm{pH} 102(\mathrm{mg})\end{array}$ & $\begin{array}{c}\text { Mucilage } \\
(\mathbf{m g})\end{array}$ & $\begin{array}{c}\text { Talc } \\
(\mathbf{m g})\end{array}$ & $\begin{array}{c}\text { Magnesium } \\
\text { stearate }(\mathbf{m g})\end{array}$ & $\begin{array}{c}\text { Sodium saccharin } \\
(\mathbf{m g})\end{array}$ \\
\hline F7 & 100 & 92 & $\begin{array}{c}40(20 \mathrm{mg} \text { intra, } \\
20 \mathrm{mg} \text { extra })\end{array}$ & 8 & 5 & 5 \\
F8 & 100 & 112 & $\begin{array}{c}20(10 \mathrm{mg} \text { intra, } \\
10 \mathrm{mg} \text { extra })\end{array}$ & 8 & 5 & 5 \\
\hline
\end{tabular}


weight of tablet before water absorption, wa $=$ weight of tablet after water absorption ${ }^{[18]}$.

\section{In vitro dissolution study:}

Prepared FDTs were placed in 900 dissolution medium (phosphate buffer $\mathrm{pH} 6.8$ ) at $50 \mathrm{rpm}$ rotation speed. Temperature was maintained at $37^{\circ} \pm 0.50$. About $5 \mathrm{ml}$ aliquots from each vessel were pipetted out at interval of each one minute. Samples were withdrawn at the end of $10 \mathrm{~min}$ and were filtered through Whatman filter paper no. 41 and analysed over Shimadzu UV-1601 spectrophotometer at $223 \mathrm{~nm}^{[17]}$.

\section{RESULTS AND DISCUSSION}

The dried and coarsely powdered seeds of $O$. basilicum yielded high percent $(30 \% \mathrm{w} / \mathrm{w})$ of dried mucilage. The results of phytochemical evaluation showed the presence of carbohydrate and mucilage was substantiated with the positive result upon the treatment with listed reagents (Table 3). It was also observed that mucilage showed positive results with Dragendorff's and Hagers reagents means it contains alkaloids as shown in Table 3. Table 4 showed the results of solubility, loss on drying and ash values. $O$. basilicum mucilage was found to be soluble in distilled water and insoluble in other solvents. The ash value showed that the extraneous matter or organic matter was completely removed. It is also a useful parameter in the evaluation of crude drugs. It can also be inferred that the mucilage is non-toxic.

The quality of the plant-derived-drug can also be determined by ash left after ignition. This parameter helped to judge the identity and purity of plantderived drugs. It is a commonly applied parameter for detection of impurities, adulteration and substitution of drug. Inorganic variables like phosphates, silicates, and carbonates are removed by treating with acid. $O$. basilicum mucilage showed low levels of total ash and acid insoluble ash, which indicated low levels of contamination during collection and handling ${ }^{[14]}$.

The $O$. basilicum mucilage showed (fig. 1) broad peak at $1014 \mathrm{~cm}^{-1}$ thus there may be presence of alcohols and ether bond i.e. -C-O. The characteristic absorption in between 1631.29-1667.24 $\mathrm{cm}^{-1}$ shows the presence of alkenes and aromatic rings. ( $>\mathrm{C}=\mathrm{C}<$ alkenes), ( $-\mathrm{C}-\mathrm{C}-$ aromatic rings). From the PXRD study of $O$. basilicum mucilage (fig. 2) peak was obtained at two theta value with intensity 2012.9813. Absence of sharp and intense peak confirms that $O$. basilicum mucilage is amorphous in nature.

In the DSC study, when the $O$. basilicum mucilage was taken to study its properties at higher temperature it has exhibited a broad endotherm at $118.6^{\circ}$ as shown in fig. 3. DSC graphs supported the PXRD graph indicating amorphous nature of $O$. basilicum mucilage. As per the reported literatures, swelling was the most widely accepted general mechanism of action for tablet disintegration. Thus from Table 5 it could be concluded that the $O$. basilicum mucilage tended to swell in an aqueous medium ${ }^{[19,20]}$. When the micromeritic parameters of $O$. basilicum mucilage were evaluated, the angle of repose of mucilage was found to be $33.16 \pm 1.64^{\circ}$. Thus, the mucilage possessed passable flow property. The Cars index was found to be $21.137 \pm 0.80 \%$, thus it has fair flow property. Hausner ratio of mucilage was found to be $1.237 \pm 0.0328$ indicating that the mucilage has fair flow or not having good flow property. The particle size and size distribution analysis of $O$. basilicum mucilage by microscopy method showed that the particles of $O$. basilicum mucilage have diameters in the range of 2.5-52.5 $\mu \mathrm{m}$. The arithmetic mean diameter of mucilage

TABLE 3: PHYTOCHEMICAL EXAMINATION OF ISOLATED MUCILAGE

\begin{tabular}{lccc}
\hline Name of test & Reagents & Observation & Inference \\
\hline Mucilage test & Rheudenium red & Red colour & Mucilage present \\
Mucilage test & Aq.KOH/Water & Powder Swell & Mucilage present \\
Molish's test & Alpha napthol+alcohol+Con. $\mathrm{H}_{2} \mathrm{SO}_{4}$ & Violet ring at junction & Carbohydrates present \\
$\begin{array}{l}\text { Pentose sugar } \\
\text { HCl+crystal of phloroglucinol }\end{array}$ & Red colour & Pentose sugar present \\
Hexose sugar & Tollen's phloroglucinol & Yellow-red colour & Hexose sugar, glucose, \\
& Cobalt chloride & greenish-blue & fructose present \\
Non-reducing sugar & Fehling's and Benedict's test & No change in colour & Non-reducing sugar present \\
Starch & lodine & Blue colour & Starch present \\
Alkaloids & Dragendorff's & Orange-brown ppt. & Alkaloid present \\
Alkaloids & Hager's & Yellow ppt. & Alkaloid present \\
\hline
\end{tabular}

Phytochemical evaluation showed the presence of carbohydrate and mucilage was substantiated with the positive result upon the treatment with listed reagents and it was also observed that mucilage showed positive results with Dragendorff's and Hager's reagents means it contains alkaloids 
was found to be 11.32978. The volume surface mean diameter was found to be 112.509124. The weight moment mean diameter was found to be 140.357758 .

\section{TABLE 4: PHYTOCHEMICAL SCREENING OF} MUCILAGE

\begin{tabular}{lc}
\hline Test & Observation \\
\hline Solubility & $\begin{array}{c}\text { Soluble in distilled water, practically } \\
\text { insoluble in ethanol, acetone and } \\
\text { chloroform }\end{array}$ \\
Loss on drying & $14.66 \%$ \\
Total ash & $7.8 \%$ \\
Acid-insoluble ash & $1 \%$ \\
Water-soluble ash & $0.4 \%$ \\
\hline
\end{tabular}

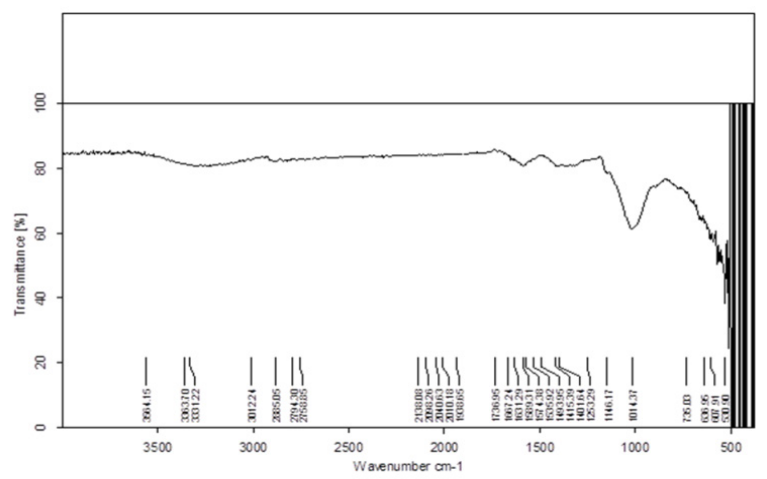

Fig. 1: FTIR spectrum of $O$. basilicum mucilage

The $O$. basilicum mucilage showed broad peak at $1014 \mathrm{~cm}^{-1}$ thus there may be presence of alcohols and ether bond i.e. $-\mathrm{C}-\mathrm{O}$

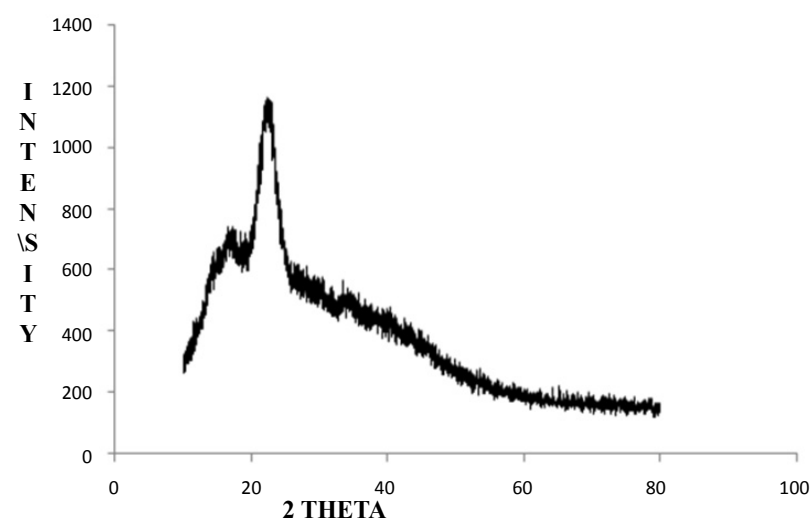

Fig. 2: PXRD of $O$. basilicum mucilage

$O$. basilicum mucilage peak was obtained at two theta value with intensity 2012.9813. Absence of sharp and intense peak confirms that $O$. basilicum mucilage is amorphous in nature
From the Heckel plot study (Tables 6 and 7) the thickness of mucilage tablets was found in between 3.1 to $4.55 \mathrm{~mm}$. Crushing strength was found to be in between 0 to $5.9 \mathrm{~kg} / \mathrm{cm}^{2}$. Tensile strength for tablets was found in between 11.7888 to $18.9446 \mathrm{~kg} / \mathrm{cm}^{2}$. Porosity was found to be 0.12676 to 28.169 . It couldn't show linear relationship for force vs. $\ln 1 / 1-r d$, no any values for the mean yield pressure. Thus from the data obtained from Heckel plot study, it can be concluded that the $O$. basilicum mucilage doesn't exert the good compressibility property. From the above study it may be concluded that $O$. basilicum seed mucilage can be used in wet granulation technology or with other excipients in direct compression studies.

Pre-compression analysis of powder blends indicates angle of repose $28.08 \pm 0.04$ to $21.83 \pm 0.1^{\circ}$ and percent compressibility of different concentrations of mucilage was found $21.41 \pm 0.01$ to $29.46 \pm 0.74 \%$. This data

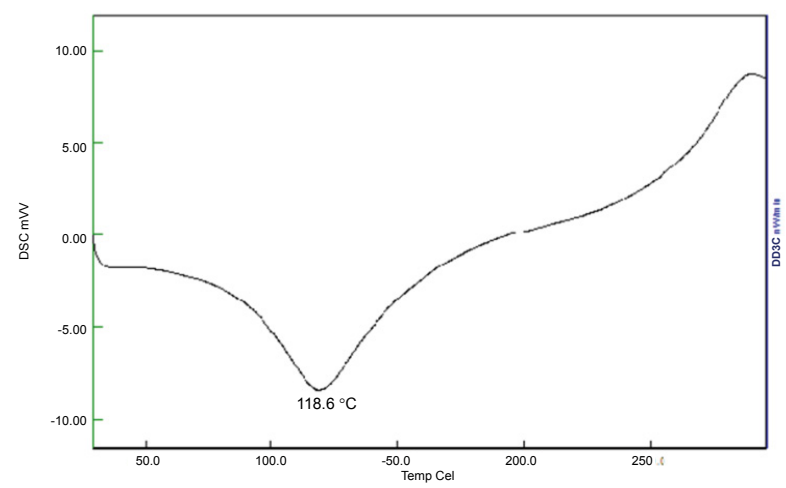

Fig. 3: DSC thermogram of $O$. basilicum mucilage

TABLE 5: SWELLING INDEX OF OCIMUM BASILICUM MUCILAGE

\begin{tabular}{lccc}
\hline $\begin{array}{l}\text { Volume } \\
\text { occupied by } \\
\text { the mucilage } \\
\text { prior to } \\
\text { hydration (V1) }\end{array}$ & $\begin{array}{c}\text { Volume } \\
\text { occupied by } \\
\text { the mucilage } \\
\text { after hydration } \\
\text { (V2) }\end{array}$ & $\begin{array}{c}\text { Swelling } \\
\text { index= } \\
\text { (V2/V1) }\end{array}$ & $\begin{array}{c}\text { Mean } \\
\text { swelling } \\
\text { index ( } \pm S D)\end{array}$ \\
\hline 2.0 & 18.02 & 9.01 & $9.16 \pm 0.12$ \\
2.0 & 24.08 & 12.04 & $12.63 \pm 0.44$ \\
2.0 & 30.2 & 15.1 & $15.6 \pm 0.66$ \\
\hline
\end{tabular}

TABLE 6: HECKEL PLOT STUDY OF O. BASILICUM MUCILAGE

\begin{tabular}{lccccc}
\hline $\begin{array}{l}\text { Pressure (tons } \\
\left.\text { or } \mathbf{k g} / \mathrm{cm}^{2}\right)\end{array}$ & $\begin{array}{c}\text { Compact weight } \\
(\mathbf{m g})\end{array}$ & $\begin{array}{c}\text { Compact thickness } \\
(\mathbf{m m})\end{array}$ & $\begin{array}{c}\text { Compact diameter } \\
(\mathbf{m m})\end{array}$ & Radius $(\mathbf{m m})$ & $\begin{array}{c}\text { Hardness } \\
(\mathbf{p a})\end{array}$ \\
\hline 25 & 500 & 3.1 & 13 & 6.5 & 4.8 \\
34.28 & 500 & 3.69 & 13 & 6.5 & 5.2 \\
51.42 & 500 & 3.56 & 13 & 6.5 & 4.1 \\
68.57 & 500 & 3.33 & 13 & 6.5 & 4.5 \\
85.71 & 500 & 4.55 & 13 & 6.5 & 5.1 \\
102.85 & 500 & 3.61 & 13 & 6.5 & 4 \\
120 & 500 & 3.55 & 13 & 6.5 & 5.9 \\
\hline
\end{tabular}


suggest that the powder blends possess fair passable flow property. The bulk density and tapped density was found in the range of $0.352-0.356$ and $0.432-0.530$ as shown in Table 8.

The granules prepared by wet granulation technique (F7-F8) exhibited angle of repose $20.69 \pm 0.36$ and percent compressibility $16.05 \pm 0.47$. Thus granules possessed good flow property. The granules showed improvement in Hausner ratio 1.17 and thus exhibited free flowing property. The Bulk density and tapped density was found to be $0.434 \pm 0.3$ and $0.44 \pm 0.02 \mathrm{~g} / \mathrm{cm}^{3}$, respectively. From this data it could be concluded that the granules possessed improved micromeritic properties than powder blends ready for compression.

As shown in Table 9, wetting time has very close correlation with disintegration. This is an important criterion for understanding the capacity of disintegrants to swell in presence of little amount of water. Since the dissolution process of a tablet depends upon the wetting followed by disintegration of the tablet, the measurement of wetting time may be used as another confirmative test for the evaluation of dispersible tablets $^{[21]}$. The wetting time of formulated tablets was found in the range of $13.6 \pm 0.30$ to $50.4 \pm 0.08 \mathrm{~s}$. The less wetting time was observed for tablets prepared using $60 \mathrm{mg}$ concentration compared to tablets prepared with 45, 50, $55 \mathrm{mg}$ concentration and CCS and SSG tablets as shown in Table 9. The results are quite improved for the F7 and F8 batch this might be due to disintegrants can be mixed with other ingredients prior to granulation and thus be incorporated within the granules (intragranular addition). It is also common for the disintegrant to be mixed with the dry granules before the complete powder mix is compacted (extragranular addition). The latter procedure would contribute to an effective disintegration of the tablet into smaller fragments ${ }^{[22]}$. In this investigation disintegrants were incorporated

TABLE 7: HECKEL PLOT STUDY OF O. BASILICUM MUCILAGE

\begin{tabular}{lccccc}
\hline Density $(\mathbf{g} / \mathrm{mmc})$ & Relative density (RD) & 1/1-rd & In 1/1-rd & porosity & Tensile strength $\left(\mathbf{k g} / \mathrm{cm}^{2}\right)$ \\
\hline 1.21577147 & 1.14516 & -6.88889 & NUM & -0.12676 & - \\
1.02137983 & 0.96206 & 26.3571 & 3.27174 & 3.94366 & 15.6651 \\
1.05867741 & 0.99719 & 356 & 5.87493 & 0.28169 & 11.9162 \\
1.13179927 & 1.06607 & -15.1364 & \#NUM! & -6.19718 & 12.2338 \\
0.82832782 & 0.78022 & 4.55 & 1.51513 & 28.169 & 18.9446 \\
1.04401429 & 0.98338 & 60.1667 & 4.09712 & 1.69014 & 11.7888 \\
1.0616596 & \#DIV/O! & \#DIV/O! & \#DIV/O! & - & 17.0995 \\
\hline
\end{tabular}

TABLE 8: PRECOMPRESSION ANALYSIS OF POWDER BLEND PREPARED FOR DIRECT COMPRESSION (F1-F6) AND PREPARED GRANULES (F7-F8)

\begin{tabular}{lcccccc}
\hline $\begin{array}{l}\text { Formulation } \\
\text { code }\end{array}$ & $\begin{array}{c}\text { Bulk density } \\
\left(\mathbf{g} / \mathrm{cm}^{3}\right)\end{array}$ & $\begin{array}{c}\text { Tapped density } \\
\left(\mathbf{g} / \mathrm{cm}^{3}\right)\end{array}$ & Hausner ratio & Flow rate (s) & $\begin{array}{c}\text { Angle of repose } \\
(\Theta)\end{array}$ & $\begin{array}{c}\% \\
\text { Compressibility }\end{array}$ \\
\hline F1 & $0.352 \pm 0.02$ & $0.530 \pm 0.016$ & $1.406 \pm 0.03$ & $0.229 \pm 0.01$ & $26.5 \pm 0.08$ & $29.46 \pm 0.74$ \\
F2 & $0.353 \pm 0.002$ & $0.432 \pm 0.003$ & $1.22 \pm 0.02$ & $0.418 \pm 0.001$ & $26.17 \pm 0.57$ & $18.26 \pm 0.04$ \\
F3 & $0.338 \pm 0.02$ & $0.460 \pm 0.02$ & $1.23 \pm 0.02$ & $0.343 \pm 0.01$ & $28.08 \pm 0.04$ & $21.41 \pm 0.01$ \\
F4 & $0.339 \pm 0.02$ & $0.452 \pm 0.001$ & $1.23 \pm 0.02$ & $0.314 \pm 0.005$ & $25.77 \pm 0.96$ & $20.25 \pm 0.02$ \\
F5 & $0.356 \pm 0.004$ & $0.49 \pm 0.004$ & $1.4 \pm 0.03$ & $0.516 \pm 0.02$ & $21.83 \pm 0.1$ & $27.30 \pm 1.06$ \\
F6 & $0.34 \pm 0.008$ & $0.46 \pm 0.01$ & $1.26 \pm 0.03$ & $0.514 \pm 0.05$ & $25.82 \pm 0.61$ & $22.47 \pm 0.37$ \\
F7 & $0.434 \pm 0.3$ & $0.44 \pm 0.02$ & $20.69 \pm 0.36$ & $0.356 \pm 0.01$ & $1.17 \pm 0.05$ & $16.05 \pm 0.47$ \\
F8 & $0.40 \pm 0.01$ & $0.48 \pm 0.05$ & $21.90 \pm 0.55$ & $0.355 \pm 0.002$ & $1.2 \pm 0.007$ & $16.66 \pm 1.25$ \\
\hline
\end{tabular}

TABLE 9: RESULTS OF POST COMPRESSION EVALUATION PARAMETERS

\begin{tabular}{lcccc}
\hline Formulation code & Wetting time $(\mathbf{s})$ & Water absorption ratio $\%$ & Disintegration time $(\mathbf{s})$ & Hardness $\left(\mathbf{k g} / \mathrm{cm}^{2}\right)$ \\
\hline F1 & $50.4 \pm 0.08$ & $64.59 \pm 0.12$ & $48.65 \pm 0.15$ & $3.7 \pm 0.08$ \\
F2 & $28.66 \pm 0.04$ & $78.93 \pm 0.03$ & $56.03 \pm 0.04$ & $3.1 \pm 0.08$ \\
F3 & $41.03 \pm 0.009$ & $84.56 \pm 0.02$ & $37.79 \pm 0.06$ & $3.16 \pm 0.04$ \\
F4 & $13.6 \pm 0.30$ & $93.46 \pm 0.33$ & $11.33 \pm 0.47$ & $3.66 \pm 0.16$ \\
F5 & $27.83 \pm 0.22$ & $84.56 \pm 0.02$ & $28.16 \pm 0.36$ & $4.2 \pm 0.21$ \\
F6 & $62.33 \pm 2.05$ & $66.75 \pm 0.34$ & $52.33 \pm 2.05$ & $3.8 \pm 0.08$ \\
F7 & $11.05 \pm 0.8$ & $96.77 \pm 0.56$ & $5.66 \pm 0.16$ & $3.6 \pm 0.14$ \\
F8 & $10.11 \pm 1.0$ & $95.59 \pm 1.2$ & $6.80 \pm 0.58$ & $3.5 \pm 0.87$ \\
\hline
\end{tabular}

Wetting time has very close correlation with disintegration 


\section{TABLE 10: RESULTS OF POST COMPRESSION EVALUATION PARAMETERS}

\begin{tabular}{lccccc}
\hline $\begin{array}{l}\text { Formulation } \\
\text { code }\end{array}$ & Thickness $(\mathrm{mm})$ & Friability \% & Drug content $(\%)$ & Tablet Weight $(\mathrm{mg})$ & $\begin{array}{c}\text { In vitro drug release (\%) at } \\
\text { the end of } 7 \text { min }\end{array}$ \\
\hline F1 & $3.59 \pm 0.06$ & $0.866 \pm 0.02$ & $96.55 \pm 0.10$ & $253.58 \pm 1.52$ & $73.88 \pm 0.10$ \\
F2 & $3.67 \pm 0.03$ & $0.70 \pm 0.06$ & $89.92 \pm 0.2$ & $250.83 \pm 0.79$ & $85.93 \pm 0.08$ \\
F3 & $3.47 \pm 0.01$ & $0.81 \pm 0.01$ & $98.52 \pm 0.01$ & $249.13 \pm 0.68$ & $90.57 \pm 0.34$ \\
F4 & $3.62 \pm 0.02$ & $0.9 \pm 0.03$ & $95.25 \pm 0.05$ & $247.91 \pm 0.18$ & $98.44 \pm 0.23$ \\
F5 & $3.72 \pm 0.23$ & $0.89 \pm 0.04$ & $85 \pm 0.07$ & $250.49 \pm 0.50$ & $80.74 \pm 0.27$ \\
F6 & $3.48 \pm 0.14$ & $0.77 \pm 0.03$ & $104.66 \pm 1.24$ & $253.42 \pm 0.69$ & $73 \pm 0.81$ \\
F7 & $3.42 \pm 0.06$ & $0.72 \pm 0.05$ & $97.80 \pm 0.21$ & $249.27 \pm 1.63$ & $99.43 \pm 2.04^{*}$ \\
F8 & $3.62 \pm 0.02$ & $0.92 \pm 0.02$ & $98.99 \pm 1.02$ & $251.76 \pm 0.89$ & $99.63 \pm 1.90^{*}$ \\
\hline
\end{tabular}

${ }^{*}$ At the end of $6 \mathrm{~min}$

as both an intragranular and an extragranular portion may improve the performance at a low concentration in comparison with direct compression technology.

Disintegration is the most important and basic phenomenon for $\mathrm{FDTs}^{[23]}$. The performance of a drug is primarily influenced by the disintegration and dissolution behaviour of the powder compact ${ }^{[24]}$. The disintegration time of the formulated tablets was found in the range of $5.66 \pm 0.16$ to $56.03 \pm 0.04 \mathrm{~s}$. The hardness was found to be in the range of $3.1 \pm 0.08$ to $4.2 \pm 0.21 \mathrm{~kg} / \mathrm{cm}^{2}$ for all formulations, which indicated good mechanical strength with an ability to withstand physical and mechanical stress conditions while handling ${ }^{[24-28]}$.

In vitro drug release of all designed formulations using $O$. basilicum mucilage powder showed rapid dissolution at the end of $7 \mathrm{~min}$. was between $73.88 \pm 0.10$ to $98.44 \pm 0.23 \%$. Whereas the tablets prepared by CCS and SSG showed drug in vitro drug release $80.74 \pm 0.27$ $73 \pm 0.81 \%$. Tablets prepared by wet granulation shows in vitro drug release $99.43 \pm 2.04$ and $99.63 \pm 1.90$ within six minutes. All other parameters were in acceptable range as shown in Table 10.

The isolated mucilage was evaluated for compressibility performance, from the Heckel plot study, it was observed that isolated mucilage has poor compressibility properties to form compacts but with other excipient it gets improved. Results showed that mucilage is a potential superdisintegrant in formulation of FDT of metoprolol tartarate. The ways of addition of mucilage, concentration and method of preparation have an effect on FDT performance. From the above study it may be concluded that $O$. basilicum seed mucilage can be used indirect compression and wet granulation technology as a superdisintegrant.

\section{Acknowledgements:}

The authors are grateful to the Principal, Government
College of Pharmacy, Karad for providing all the necessary laboratory facilities.

\section{Conflicts of interest:}

There are no conflicts of interest.

\section{Financial support and sponsorship:}

Nil.

\section{REFERENCES}

1. Patil PS. Natural excipients: Uses of pharmaceutical formulations. Int J Pharm Tech Res 2014;21-8.

2. Kamble MS, Chaudhari. Evaluation of Binding Property of Ocimum tenuiflorum Linn. Seed mucilage isolated by Defatting method. J Biomed Pharm Res 2012;3:22-7.

3. Jania GK, Shah DP, Prajapatia VD, Jain VC. Gums and mucilages: versatile excipients for pharmaceutical formulations. Asian J Pharm Sci 2009;4:308-22.

4. Malviya R, Srivastava P, Kulkarni GT. Applications of mucilages in drug delivery -a review. Adv Biol Res 2011;5:1-7.

5. Bhasin M. Ocimum-taxonomy, medicinal potentialities and economic value of essential oil. J Biosphere 2012;1:48-50.

6. Al Abbasy DW, Nirmal P, Al-Sabahi JN, Khan SA. Chemical composition and antibacterial activity of essential oil isolated from Omani basil (Ocimum basilicum Linn.). Asian Pac J Trop Dis 2015;5:645-9.

7. Naji-Tabasi S, Mohammad Ali SR, Mohebbat M, MalaekehNikouei B. New studies on basil (Ocimum bacilicum L.) seed gum: Part I Fractionation, physicochemical and surface activity characterization. Food Hydrocoll 2016;52:350-8.

8. Naimeh K, Mohsen E, Zahra ED, Mehran G, Joukida MD. Characterization of new biodegradable edible film made from basil seed (Ocimum basilicum L.) gum. Carbohydr Polym 2014;102:199-206.

9. Sorour S, Naz C, Ali Reza P, Sam Ha. Mucilaginous seed of Ocimum basilicum as a natural coagulant for textile wastewater treatment. Ind Crops Prod 2015; 69:40-7.

10. Reddy MS, Srividyalalitha T. Formulation and evaluation of fast disintegrating Tablets of lamivudine using Ocimum basilicum seed Mucilage as superdisintegrant. World J Pharm Res 2014;3:1292-304.

11. More HN, Hajare A. Practical pharmaceutics (Physical pharmacy). Pune: Manas Prakashan; 2008. p. 90-7.

12. Aulton ME. Pharmaceutics: The science of dosage form 
design. 1st ed. New York: Churchill Livingstone; 1988. p. 250-2 and 425-9.

13. Denny PJ. Compaction equations: a compaction of the Heckel and Kawakita equations. Powder Technol 2009;127:162-72.

14. Sonneguard JM. A critical equation of the Heckel equation. Int J Pharm 1999:193;63-71.

15. Martin A, Swarbrick J, Cammarata A, Chun AHC. Physical pharmacy, physical and chemical principles in the pharmaceutical sciences. Bombay: Varghese Publishing House; 1991.

16. Staniforth JN. Powder flow. In: Pharmaceutics: The science of dosage form design. Aulton ME, editor. 1st ed. London: Churchill Livingstone; 1988. p. 610-13.

17. Indian Pharmacopoeia. Vol. 2. Delhi: The Controller of Publication, Govt. of India, Ministry of Health and Family Welfare.; 1996. p. 242-43.

18. Abdelbary G, Prinderre P, Eouani C, Joachim J, Reynier JP, Piccerelle P. The preparation of orally disintegrating tablets using a hydrophilic waxy binder. Int $\mathrm{J}$ Pharm 2004:278:423-33.

19. Lachman N, Liberman HA. The theory and practice of industrial pharmacy. 3rd ed. Mumbai: Varghese Publishing House; 1987. p. 66-9.

20. Banker GS, Anderson NR. Tablets. In: Lachman N, Liberman HA. The Theory and Practice of Industrial Pharmacy. 3rd ed. Mumbai: Varghese Publishing House; 1987. p. 296-317.
21. Kumar R, PatilM B, PatilS R, Paschapur MS. Evaluation of disintegrating properties of Abelmoschus esculentus mucilage. Int J PharmTech Res 2009:1;241-6.

22. Aulton ME. Pharmaceutics. The Science of Dosage Form Design. 1st ed. London: Churchill Livingstone; 1988. p. 133136, 250-52, 406-40.

23. Uebbing L, Klumpp L, Webster GK, Löbenberg R. Justification of disintegration testing beyond current FDA criteria using in vitro and in silico models. Drug Des Devel Ther 2017;11:1163-74.

24. Bala R, Khanna S, Pawar P. Polymers in fast disintegrating tablets - A review. Asian J Pharm Clin Res 2012:5;8-14.

25. Malviya R. Extraction Characterization and Evaluation of Selected Mucilage as Pharmaceutical Excipient. Polim Med 2011;41(3):39-44.

26. Malke S. Shidhaye S, Kadam VJ. Formulation and evaluation of Oxicarbazepine fast dissolve tablets. Indian J Pharm Sci 2007;69:211-4.

27. http: \www.pharmainfo.net/reviews/new-generation- tabletfast-dissolving-tablet.

28. Bal T, Murthy PN, Sengupta S. Isolation and analytical studies of mucilage obtained from the seeds of Dillenia indica (family Dilleniaceae) by use of various analytical techniques. Asian J Pharm Clin Res 2012;5:65-8. 